\title{
Methylphenidate for the amelioration of cancer-associated fatigue
}

\author{
Shailendra Kapoor
}

Received: 2 April 2012 / Accepted: 30 April 2012 / Published online: 9 May 2012

(C) Springer-Verlag 2012

To the editor:

I read with great interest the recent article by Romito et al. in a recent issue of your esteemed journal [1]. The article is highly thought provoking. Interestingly, recent studies have shown the significant effectiveness of psycho-stimulants such as methylphenidate in attenuating cancer-associated fatigue.

For instance, both the "Brief Fatigue Inventory severity scores" and the "Brief Fatigue Inventory total scores" are decreased in prostate cancer patients following methylphenidate therapy [2]. Similarly, Cueva et al. in a recent study have shown the effectiveness of methylphenidate in attenuating asthenia in breast carcinoma patients who received chemotherapy with agents such as docetaxel [3].

Significant improvement in the quality of life index as well as a corresponding attenuation of fatigue is seen in patients with recurrent gynecological carcinomas following methylphenidate therapy [4]. Interestingly, marked improvement in fatigue has been seen after "patient-controlled" methylphenidate administration [5]. Treatment response at the initiation of therapy is a good predictor of ultimate and long-term response to methylphenidate therapy [6].

However, the blood pressure needs to be monitored closely in cancer patients on methylphenidate therapy. The above studies clearly demonstrate the effectiveness of methylphenidate in ameliorating cancer-associated fatigue. Hopefully, the coming few years will see an increased use of methylphenidate for the management of fatigue in patients with advanced and end-stage cancers.

Conflict of interest None.

\section{References}

1. Romito F, Cormio C, Giotta F, Colucci G, Mattioli V (2012) Quality of life, fatigue and depression in Italian long-term breast cancer survivors. Support Cancer Care. doi:10.1007/s00520-012-1424-9

2. Roth AJ, Nelson C, Rosenfeld B et al (2010) Methylphenidate for fatigue in ambulatory men with prostate cancer. Cancer 116:51025110

3. Cueva JF, Calvo M, Anido U et al (2012) Methylphenidate in the management of asthenia in breast cancer patients treated with docetaxel: results of a pilot study. Invest New Drugs 30:688-694

4. Johnson RL, Block I, Gold MA, Markwell S, Zupancic M (2010) Effect of methylphenidate on fatigue in women with recurrent gynecologic cancer. Psychooncology 19:955-958

5. Bruera E, Valero V, Driver L et al (2006) Patient-controlled methylphenidate for cancer fatigue: a double-blind, randomized, placebocontrolled trial. J Clin Oncol 24:2073-2078

6. Yennurajalingam S, Palmer JL, Chacko R, Bruera E (2011) Factors associated with response to methylphenidate in advanced cancer patients. Oncologist 16:246-253 